\title{
CONTRIBUIÇÃO DA PRESENÇA DO EOSINÓFILO NO ESCARRO AO DIAGNÓSTICO DAS ALTERAÇÕES PULMONARES PÓS-TRATAMENTO NA ESQUISTOSSOMOSE MANSONI HUMANA CRÔNICA. ESTUDO DUPLO-CEGO
}

\author{
Ênio Roberto Pietra Pedroso, José Roberto Lambertucci, Manoel Otávio Costa Rocha, \\ Dirceu Bartolomeu Greco, Pedro Raso, \\ Cid Sérgio Ferreira e Davidson Pires de Lima
}

\begin{abstract}
Em estudo duplo-cego observou-se que as alterações radiológicas pulmonares após tratamento com oxamniquine de pacientes com esquistossomose mansoni crônica associam-se com a presença de eosinófilos no escarro $(p<0,01)$. Este fenômeno reforça os achados experimentais e humanos sobre a presença de hipersensibilidade tipo I e III na esquistossomose mansoni em tratamento.
\end{abstract}

Palavras chaves: Esquistossomose mansoni. Broncopneumonite pós-tratamento. Eosinófilos no escarro. Broncopneumonite eosinofilica.

Cerca de $25 \%$ dos pacientes com esquistossomose mansoni crônica podem evoluir, até sete dias após tratamento com oxamniquine, com alteraçōes radiológicas pulmonares 79 . Estas alterações parecem estar relacionadas com reações de hipersensibilidade tipos I e III a nível pulmonar 457 . Suas repercussões clínicas são pouco significativas, apesar de se poder evidenciar, radiologicamente, padrões de broncopneumonite ${ }^{7}$. Tal achado induz o clínico muitas vezes a prescrever, desnecessariamente, antibióticos.

A expectoração é manifestação comum e importante das doenças do aparelho respiratório, sendo que as alteraçōes broncopneumônicas podem ser reveladas por anormalidades do escarro, verificadas pelo exame macro- e microscópico, com técnicas não invasivas e de fácil realização.

As alterações radiológicas pulmonares póstratamento comportam-se como infiltração pulmonar simples ${ }^{7}$ sendo que os achados no exame do escarro não foram ainda descritos. $O$ eosinófilo pode ter papel de importância nas reações antigeno-anticorpo, envolvendo-se nas reações de hipersensibilidade, especialmente dos tipos I e III 3 .

O objetivo deste trabalho é analisar o escarro em função das alterações radiológicas pulmonares pos-

Núcleo de Estudos sobre Esquistossomose. Faculdade de Medicina. UFMG. Financiado parcialmente pelo CNPq. Departamento de Clínica Médica da Faculdade de Medicina da Universidade Federal de Minas Gerais. Av. Alfredo Balena, 190, Belo Horizonte, 30.000, Minas Gerais, Brasil. Recebido para publicação em 6/2/84. tratamento na esquistossomose mansoni, em estudo duplo-cego. Procurou-se correlação entre presença de eosinófilos no escarro e alterações radiológicas pulmonares pós-tratamento com oxamniquine.

\section{MATERIAL E MÉTODOS}

Foi realizado estudo duplo-cego em 81 pacientes de ambos os sexos, com idade variando entre sete a quarenta anos. Foram tratados 49 pacientes com oxamniquine, via oral, $20 \mathrm{mg} / \mathrm{kg}$ de peso, dose única e 32 com placebo (amido) em cápsulas semelhantes às da oxamniquine. Após o término do estudo, os pacientes que haviam recebido placebo foram tratados especificamente.

Todos os pacientes foram submetidos à telerradiografia do tórax antes e diariamente até o sétimo dia após o tratamento. A análise radiológica foi realizada independentemente, por três pessoas e considerada alterada quando pelo menos dois laudos eram coincidentes.

O diagnóstico da esquistossomose mansoni crônica baseou-se no encontro de ovos viáveis de $S$. mansoni nas fezes. Excluiu-se a participação de parasitos intestinais pela realização de seis exames parasitológicos de fezes (Kato-Katz, Baermann-Morais). Todos os pacientes eram portadores da forma hepatintestinal da esquistossomose mansoni.

A pesquisa de eosinófilos no escarro foi feita por um mesmo observador, três exames em dias diferentes antes do tratamento e uma amostra, diariamente, até o sétimo dia após o tratamento. $\mathrm{O}$ escarro foi examinado 
Pedroso ERP, Lambertucci JR, Rocha MOC, Greco DB, Raso P, Ferreira CS, Lima DP. Contribuiçāo da presença do eosinófilo no escarro ao diagnóstico das alteracóes pulmonares pós-tratamento na esquistossomose mansoni humana crónica. Estudo duplo-cego. Revista da Sociedade Brasileira de Medicina Tropical 17: 77-79, Abr-Jun, 1984

em lâmina, após fixação do esfregaço e secagem ao ar. A coloração foi feita pelo método de Leishman. $O$ resultado foi considerado positivo quando a pesquisa dos eosinófilos de negativa antes do tratamento se tornou positiva após. Todas as outras combinações foram consideradas negativas. $O$ escarro foi também submetido às colorações pelo Gram, Ziehl-Nielsen, pesquisa de fungos e citologia.

O estudo do leucograma se fez nos dias zero, terceiro, quinto e sétimo após o tratamento. Os dados de cada variável foram sumarizados em tabelas de contingências. A comparação foi feita pelo teste do Qui quadrado. $\mathrm{O}$ nível de significância minimo necessário foi de $5 \%$.

\section{RESULTADOS}

Entre os pacientes tratados com oxamniquine, 12 tiveram alterações radiológicas pulmonares póstratamento e, dentre eles, nove $(75 \%)$ apresentaram eosinófilos no escarro. Entre os 37 sem alterações radiológicas pulmonares após o tratamento com oxamniquine, nove apresentaram eosinófilos no escarro $(24 \%)$. A presença de eosinófilo no escarro em função de alterações radiológicas pulmonares póstratamento com oxamniquine foi significativa $(\mathrm{p}<0,01)$. Entre os pacientes que receberam placebo não houve mudanças no padrão radiológico pulmonar. Nesse grupo encontrou-se eosinófilos no escarro em $9(28 \%)$. Não houve diferença significativa entre a presença de eosinófilos no escarro entre os pacientes sem alterações radiológicas pulmonares após oxamniquine com os que receberam placebo (Tabela 1). Em nenhum dos casos houve modificações quantitativas e qualitativas da flora ao Gram, sendo negativa a pesquisa de fungos e Baar. A citologia foi classe I. O leucograma não mostrou alterações.

Tabela 1-Eosinófilos no escarro em função de alterações radiológicas pulmonares póstratamento com oxamniquine ou placebo.

\begin{tabular}{lrrrrrrr}
\hline \multirow{2}{*}{$\begin{array}{c}\text { Eosinófilos } \\
\text { no }\end{array}$} & \multicolumn{4}{l}{$\begin{array}{l}\text { Alteraçóes radiológicas pulmonares } \\
\text { escarro }\end{array}$} & Oxamniquine & \multicolumn{3}{c}{ Placebo } & Total \\
\cline { 2 - 6 } & \multicolumn{1}{c}{ Sim } & Não & Total & Sim & Não & Total & \\
\hline Sim & 9 & 9 & 18 & 0 & 9 & 9 & 27 \\
Não & 3 & 28 & 31 & 0 & 23 & 23 & 54 \\
Total & 12 & 37 & 49 & 0 & 32 & 32 & 81 \\
\hline
\end{tabular}

\section{DISCUSSÃO}

A broncopneumonite após tratamento com oxamniquine em pacientes com fase crônica da esquistossomose mansoni parece representar reações de hipersensibilidade tipos I e III4 57 aos antigenos do verme 57 a nível pulmonar. Não representam a chamada pneumonite por verme morto descrita com uso de antimoniais 18 11. As alterações são suficientemente intensas para permitirem reconhecimento radiológico 67

O diagnóstico diferencial, entretanto, requer exclusão de reação à droga e de presença de bactérias, virus, fungos e helmintos. $\mathrm{O}$ quadro clínico, o leucograma, o Gram, Baar, pesquisa de fungos e citologia do escarro permitem excluir as possibilidades clínicas das pneumonites bacterianas comuns, víricas, fúngicas, atipicas, da tuberculose e da doença dos legionários. Não permite diferenciar reações de hipersensibilidade devidas à droga isoladamente das relacionadas aos produtos de desintegração do verme. Como se verifica nos resultados, nove pacientes tratados com oxamniquine, sem alterações radiológicas pulmonares pós-tratamento apresentaram eosinófilos no escarro. Neste caso a droga poderia ser responsabilizada diretamente pelo encontro dos eosinófilos no escarro ou o método radiológico não ser suficientemente capaz de discernir pequenas alterações pulmonares. A presença do grupo placebo, entretanto, permite discutir estas duas possibilidades. Não se verificou associação estatisticamente significativa entre a presença de eosinófilos no escarro dos pacientes sem alteraçōes radiológicas pulmonares pós-tratamento em função do uso de oxamniquine ou placebo. Este fato permite excluir a droga como responsável, isoladamente, pela broncopneumonite aqui relatada, exclui associação entre presença de eosinófilos no escarro e esquistossomose mansoni crônica e afirma que o método de avaliação das alterações pulmonares é suficientemente fidedigno. A presença de eosinófilos no escarro nos grupos sem alterações radiológicas pulmonares após tratamento com oxamniquine se deve, provavelmente, à distribuição normal na população.

Essas observações indicam que a presença de eosinófilos no escarro pode orientar o diagnóstico das alterações radiológicas pulmonares e permite a conclusão de que as alterações radiológicas pulmonares que surgem após o tratamento com oxamniquine são secundárias à reação de hipersensibilidade aos produtos do verme a nível pulmonar desencadeadas pela droga. 
Pedroso ERP, Lambertucci JR, Rocha MOC, Greco DB, Raso P, Ferreira CS, Lima DP. Contribuição da presença do eosinófilo no escarro ao diagnóstico das alteraçóes pulmonares pós-tratamento na esquistossomose mansoni humana crônica. Estudo duplo-cego.Revista da Sociedade Brasileira de Medicina Tropical 17: 77-79, Abr-Jun, 1984

Esse estudo realizado no homem corrobora as evidências experimentais 4510 e humanas 2710 de reação de hipersensibilidade I e III $^{4} 57$ na esquistossomose mansoni.

\section{$S U M M A R Y$}

In a double-blind study, the post-oxamniquine $X$-ray pulmonary alterations were associated with sputum eosinophilia $(p<0.01)$. This suggests the occurrence of a hypersensitivity reaction in treated human schistosomiasis mansoni infections.

Key words: Schistosomiasis mansoni. Posttreatment bronchopneumonitis. Eosinophils in sputum. Eosinophilic bronchopneumonitis.

\section{REFERÊNCIAS BIBLIOGRÁFICAS}

1. Coura JR, Coutinho SG, Morais HM, Dias LB, Rodrigues NP, Silva JR. Esquistossomose pulmonar. Hospital 63: 31-50, 1963.

2. Falcão A, Gould DB. Immune complex nephropathy in schistosomiasis. Annals of Internal Medicine 83: 148$54,1975$.

3. Gell PG, Coombs RRA. Clinical aspects of immunology. Oxford, Blackwell Scientific Publications, 1968.

4. Greco DB. Infecção por Schistosoma mansoni e deposição de imune-complexos no pulmão. Estudo experimental. Tese de doutorado, Universidade Federal de Minas Gerais, Belo Horizonte, 1980.

5. Greco DB, Lambertucci JR, Coelho PMZ, Silva FCL, Pedroso ERP, Rocha MOC, Caiaffa W, Raso P, Salazar HM. Deposition of immunoglobulin, complement and antigens of Schistosoma mansoni, in lung, in experimentally infected mice. A model of immune complex disease. In: Abstracts, International Congress of Immunology 4, Paris, pp. 21-26, 1980.

6. Pedroso ERP, Neves J, Marinho RP, Lambertucci JR, Souza DWC, Rocha MOC. Esquistossomose pulmonar crônica IV. Alterações pulmonares pós-tratamento com oxamniquine. In: Resumos dos temas livres do XIV Congresso da Sociedade Brasileira de Medicina Tropical, João Pessoa, p. 112, 1978.

7. Pedroso ERP. Contribuição ao estudo da esquistossomose mansoni humana e experimental. Especial referência às alterações clínico-radiológicas do pulmão após tratamento especifico. Pulmão modelo imunopatológico da doença esquistossomótica. Tese de doutorado, Universidade Federal de Minas Gerais, Belo Horizonte, 1982.

8. Prata A, Machado R. Alterações pulmonares observadas no tratamento antimonial da esquistossomose. Revista do Instituto de Medicina Tropical de São Paulo 2: 29-36, 1960.

9. Silva LC, Sette Jr. H, Christo C, Raia S. Alterações pulmonares e renais após administração de oxamniquine a dois pacientes com esquistossomose hepatosplênica (HE). In: Resumos dos temas livres do XIV Congresso da Sociedade Brasileira de Medicina Tropical, João Pessoa, p. 130, 1978.

10. Warren KS. The immunopathogenesis of schistosomiasis: a multidisciplinary approach. Transactions of the Royal Society of Tropical Medicine and Hygiene 66: 417-34, 1972.

11. Zanandréa B, Pereira OA, Nascimento SR. Eosinofilia pós-antimonial na esquistossomose mansoni. Medicina Cirurgia e Farmácia 279: 304-8, 1959. 